\title{
Risk factors and postoperative complications in oncologic surgeries
}

\section{Fatores de risco e complicações pós operatórias em cirurgia oncológica}

\author{
Suzane Cristina Santos $\mathbb{C D}^{[a]}$, Andersom Ricardo Fréz ${ }^{[b]}\left[\mathbb{C}\right.$, João Afonso Ruaro ${ }^{[b]} \mathbb{C}^{\mathbb{C}}$, Jéssica Wouk ${ }^{[b]}$ \\ Christiane Riedi Daniel (iD [b]*
}

[a] Universidade Estadual do Oeste do Paraná (UNIOESTE), Cascavel, PR, Brazil

[b] Universidade Estadual do Centro-Oeste (UNICENTRO), Guarapuava, PR, Brazil

\section{Abstract}

Introduction: Oncological patients who are submitted to surgical procedures might have postoperative pulmonary complications (PPCs). Thus, preoperative physical conditions must be considered, since it is an important predictor of postoperative development. Objective: The purpose of this study was to analyze the risk factors for postoperative pulmonary complications that might compromise the recovery after oncologic surgery. Method: The present observational transversal study was made between March and October of 2015. Patients diagnosed with cancer were analyzed to determine pulmonary and functional condition and to identify the risk factors for the development of PPCs. The post-surgery recovery was followed through medical records. Data collected from patients' analyses was correlated with post-surgery development. Results: Thirty patients were analyzed. A negative and moderate correlation was found between maximal inspiratory pressure (MIP) and PPCs ( $\mathrm{r}=-0.39$; $\mathrm{p}=0.032)$. A positive correlation between the time of permanence in the Intensive Care Unit (ICU) and hospitalization days ( $\mathrm{r}=0.40 ; \mathrm{p}=0.02)$ was observed. Correlations between PPCs and mechanical ventilation ( $\mathrm{r}=0.36 ; \mathrm{p}=0.04)$ and hospitalization days $(\mathrm{r}=0.40 ; \mathrm{p}=0.02)$ were also noticed in the present study. Conclusion: PPCs might prejudice post-surgery outcome. The greater are physical condition and pulmonary functions of the patients before surgery, the better is their recovery.

Keywords: Surgery. Cancer. Post-Surgery Complications. Pulmonary Function. Physiotherapy.

\footnotetext{
*SCS: MS, email: suzanecristinaa@gmail.com ARF: Doctoral student, email: frez@unicentro.br JAR: PhD, email: joaoruaro@bol.com.br JW: Doctoral student, email: je_wouk@hotmail.com CRD: PhD, email: christiane_riedi@hotmail.com
} 


\section{Resumo}

Introdução: Pacientes oncológicos submetidos a procedimentos cirúrgicos podem apresentar complicações pulmonares no pós-operatório. A condição física pré-operatória deve ser considerada, pois é um importante preditor do desenvolvimento pós-operatório. Objetivo: Analisar os fatores de risco para complicações pulmonares pós-operatórias (CPPO) que podem comprometer a recuperação após a cirurgia oncológica. Método: $O$ presente estudo observacional transversal foi realizado entre os meses de março e outubro de 2015. Pacientes oncológicos participaram de uma avaliação para determinação da condição pulmonar e funcional pré-operatória e identificação dos fatores de risco para desenvolvimento de CPPO. A evolução pós-operatória foi acompanhada por meio de prontuários. Os dados coletados da avaliação foram correlacionados com o desenvolvimento pós-operatório. Resultados: Trinta pacientes foram analisados. Foi encontrada correlação negativa e moderada entre a PImáx e as CPPO ( $r=-0,39 ; p=0,032)$. A permanência na UTI apresentou correlação positiva com os dias de internamento hospitalar $(r=0,40 ; p=0,02)$. A ventilação mecânica $(r=0,36 ; p=0,04)$ e os dias de internamento no hospital ( $r=0,40 ; p=0,02)$ tiveram correlação com o tipo de CPPO. Conclusão: CPPO podem prejudicar o desfecho pós-operatório. Bom estado físico e boa função pulmonar prévias à cirurgia oncológica possibilitam melhor desempenho para o paciente no pós-operatório.

Palavras-chave: Cirurgia. Câncer. Complicações Pós-Operatórias. Função Pulmonar. Fisioterapia.

\section{Introduction}

Neoplasia is a public health problem. The global cancer burden is estimated to have risen to 18.1 million new cases and 9.6 million deaths in 2018. Statistical data show that one in 5 men and one in 6 women worldwide develop cancer during their lifetime, and one in 8 men and one in 11 women die from the disease $[1,2]$. There are an estimated of 600 thousand new cases of cancer in Brazil between 2018 and 2019, for each year, excluding nonmelanoma skin cancer (about 170.000 new cases), 420.000 new cases of cancer will occur, and most of these patients will need surgery as treatment $[3,4]$.

Although surgeries present high cure rate, postop complications may occur, such as infections, skin injuries, lesions in the surgical incision, musculoskeletal and vascular alterations, and cardiac and pulmonary complications [5 - 7].

Surgical procedures may also be followed by respiratory dysfunctions. Anesthetics may cause hypoventilation, cough inefficiency (due to the pain), immobility and central nervous system impairment. These complications may trigger PPCs, such as diaphragmatic dysfunction, respiratory muscle weakness, post-surgery pain and alveolar collapse; these events cause a reduction of vital capacity and also, pulmonary residual functional capacity, contributing to surgical morbimortality, including time of hospitalization and its costs [8 - 13].

PPCs development is associated with a decrease in functional capacity and, consequently, with a greater difficulty in rehabilitating. Therefore, functional and physical capacities of the patients before surgery are directly correlated with their post-surgery healing process $[4,5,14]$. Physical characteristics, healthy conditions, lifestyle and decreased pulmonary functions may be considered risk factors for PPCs development $[15,16,17,6]$.

Pre-surgery evaluations of the patient's physical condition and the identification of factors that might trigger PPCs are necessary to help staff in decisionmaking, prevent complications, decrease morbidity and mortality rates, as well as provide a post-surgery recovery with effective treatments $[15,4,16]$.

Considering oncologic post-surgery complications and knowing the importance of having an adequate rehabilitation, this study aimed to evaluate the risk factors that may compromise post-surgery recovery. Understandings these factors, these 
complications could be prevented, and the patients would have an adequate functional recuperation.

\section{Methods}

The present observational transversal study was made at the Physiotherapy Educational Clinic of Universidade Estadual do Centro-Oeste (UNICENTRO) between March and October of 2015. The post-surgery recovery was followed through medical records.

\section{Participants}

The participants were recruited utilizing a list of surgery appointments which had the name, telephone number, date, and type of surgery of the patients. The triage occurred in the oncology unit of São Vicente de Paulo Hospital, located in Guarapuava city. Patients received a call in which the objectives of the present work were clarified, and the invitation to join the research was made.

Patients with neoplasia that would undergo an elective oncologic surgery for tumor resection at any surgical site, were included in the study. Some patients were excluded from the research, such as the ones who underwent surgical excision of melanoma, those for staging and diagnosis or emergency operations or/and were hemodynamically unstable. Patients that did not have physical or cognitive conditions to perform the tests were also excluded.

\section{Procedures}

Preoperative evaluations were performed, at least, 15 days before surgery. First, personal and anthropometric data were collected, as well as information about the patients' lifestyle habits and healthy conditions. Measurements of respiratory muscle strength, pulmonary function, and peripheral muscle strength were performed, as well as a six-minute walk test (6MWT).

Risk scores for PPCs development were evaluated based on Hulzebos et al. [16] system, which classifies this risk in high or low.

Patients' post-op conditions were verified using medical records, considering the necessity of staying in ICU and utilizing mechanical ventilation (MV), the hospitalization time and the outcome (hospital discharge or death).

\section{Evaluations}

Pulmonary function

Values of forced vital capacity (FVC) and forced expiratory volume in one second (FEV1) were analyzed. To perform these tests, the patients remain seated, breathing through the mouth (with the help of a nose clip) and utilizing a mouthpiece connected to the spirometer (MicroLab, Cardinal Health). Patients are instructed to exhale quickly after a deep breath. This procedure was performed three times, with free intervals, registering the best measurement [11].

\section{Respiratory muscle strength}

Respiratory muscle strength test was conducted with an analog manovacuometer (Comercial Médica, São Paulo, Brasil), calibrated in cmH20, with a -120 to $+120 \mathrm{cmH} 20$. Measurements were taken with the individuals in a seated position, wearing a nose clip and keeping a mouthpiece held firmly between the lips. Maximal inspiratory pressure (MIP) was obtained by a maximal inspiratory effort maneuver after a maximal expiration, close to the residual volume (RV). Maximal expiratory pressure (MEP) was achieved by a maximal expiratory effort, after a maximal inspiration, close to the total lung capacity (TLC) [9]. Maneuvers were performed for 2 seconds and repeated three times with free intervals, being registered the best measure. For statistical analysis, maximum values were considered. Values found for MIP and MEP were compared to those predicted by the equations of Neder et al. [18].

\section{Physical capacity}

The physical capacity test was obtained by 6MWT, performed according to American Thoracic Society [19]. The equations proposed by Enright and Sherrill [20] were utilized to estimate the distance to be covered during the $6 \mathrm{MWT}$, considering gender. 


\section{Peripheral muscle strength}

Peripheral muscle strength was estimated by handgrip strength (HGS), measured in dominant upper limb utilizing a digital dynamometer (Camry - EH101), with kilogram/strength registration $(\mathrm{kg} / \mathrm{s})$.

Participants were asked to stand and hold the dynamometer with arms at their side. Next, it was requested for them to squeeze the dynamometer with as much force as possible during 3 seconds [21]. Three trials were made, and the best result was registered for a subsequent analyze. Normative reference values were obtained from Camry Instrument Owner's Manual, which classifies the strength according to the person's age and gender [22].

\section{Determination of risk scores}

Risk scores were calculated according to Hulzebos et al. [16] proposal. A sum of risk factors and protective factors presented by each patient must be made to obtain the final score. A punctuation between -4 and -2 indicates a low risk, and between -1 to 10 indicates a high risk of developing PPCs. The risk factors are age $(\geq 70)$, productive cough, smoking, and diabetes mellitus. The protective factors are FVC and MEP $\geq 75 \%$ of the predicted value.

\section{Determination of postoperative complications}

The determination of postoperative pulmonary complications (PPCs) was based on Hulzebos et al. [16] study, which classifies the PPCs according to postoperative findings. Type I PPCs are related to dry cough or microatelectasis and temperature higher than $37.5^{\circ} \mathrm{C}$ or dyspnea. Type II refers to PPCs which involve productive cough, bronchospasm, hypoxemia with signs and symptoms of wheezing and dyspnea or atelectasis confirmed by radiology associated with temperatures higher than $37.4^{\circ} \mathrm{C}$. Type III is related to pleural effusion or suspected pneumonia, pneumothorax and reintubation with a mechanical ventilation period not greater than 42 hours. Lastly, patients with PPCs of type IV depend on the mechanical ventilator for more than 48 hours post-operation, with or without intubation.

\section{Ethical aspects}

This study was approved by the Research Ethics Committee of Universidade Estadual do Centro-Oeste (UNICENTRO) (protocol number 973.298). All participants were informed about the experiment characteristics and signed the Informed Consent Form.

\section{Statistical Analysis}

The data were expressed as mean \pm standard deviation with sample minimum, sample maximum or median, with first and third quartiles. Frequency distribution was utilized to present the characteristics of the sample.

Data normality was verified using KolmogorovSmirnov test. Once data were considered non-parametric, Spearman correlation was used to correlate the presence of PPCs with the variables evaluated before surgery, as well as the type of complication with postoperative monitoring and ICU days, mechanical ventilation, and hospitalization. After, it was assessed the correlation between the types of PPCs and the variables which presented significant correlation previously.

The correlation coefficient was measured according to Cohen [23], considering values between 0.10 and 0.29 a weak correlation, between 0.30 and $0.49 \mathrm{a}$ moderate correlation and values between 0.50 and 1 a strong correlation.

Reference values of respiratory and peripheral muscle strength, spirometric variables, and 6MWT were calculated and compared to the results found in the present study by Wilcoxon test, which is a nonparametric test.

Data of this study were analyzed by the Statistical Package for the Social Sciences (SPSS) software for Windows, version 19 and GraphPad InStat 4.3. The statistical differences were determined with a significance level of $95 \%(p \leq 0.05)$.

\section{Results}

We identified 192 patients in a list of surgery appointments. From this group, 89 patients were excluded from the study for having skin cancer, 11 for 
undergoing simple procedures for examination and 8 for not having physical conditions to perform the tests. Fifteen people did not accept to participate in this research. Also, 35 patients agreed but were not able to move to the Educational Clinic to perform the evaluation. Therefore, 34 patients completed the preoperative evaluation, and 4 canceled the surgery, resulting in a final sample of 30 patients.

The sample was composed of individuals of both genders, being the majority women. Regarding surgery indication $36.6 \%(n=11)$ were breast surgery, $33.3 \%(n=10)$ were abdominal surgery, $16 \%(n=5)$ were head and neck surgery, $6.6 \%(\mathrm{n}=2)$ were thoracic surgery and $6.6 \%(\mathrm{n}=2)$ were cases of lymph nodes resection. Anthropometric characteristics, lifestyle habits, associated diseases, and surgery background of patients are described in Table 1.

Table 1 - Patients characteristics

\begin{tabular}{lcc}
\hline Variable & Mean \pm SD & (U.L.; L.L.) \\
Age & $52.8 \pm 14.6$ & $(58.3 ; 47.4)$ \\
Weight & $68.3 \pm 18.8$ & $(75.3 ; 61.3)$ \\
Height & $163.6 \pm 9.0$ & $(184 ; 150)$ \\
BMI & $25.9 \pm 6.6$ & $(28.3 ; 23.4)$ \\
Characteristics of & N (\%) & \\
the individuals & & \\
Gender & & \\
$\quad$ Male & $6(20.0)$ & \\
$\quad$ Female & $24(80.0)$ \\
Smokers & $8(26.7)$ \\
Ex-smokers & $8(26.7)$ \\
Productive cough & $12(40.0)$ \\
Respiratory diseases & $9(30.0)$ \\
Dyspnea without etiology & $11(36.7)$ \\
SAH & $11(36.7)$ \\
DM & $3(10.0)$ \\
Sedentarism & $27(90.0)$ \\
Previous surgeries & $17(56.7)$ \\
\hline Note: SD: standard deviation; U. L.: Upper Limit; L.L: Lower Limit; BMI: body \\
mass index; SAH: systemic arterial hypertension; DM: diabetes mellitus.
\end{tabular}

Table 2 presents the values of the variables respiratory muscle strength, maximal expiratory pressure (MEP), maximal inspiratory pressure (MIP), pulmonary function, functional capacity and peripherical muscle strength. These values were obtained in the preoperative evaluation and are compared to normal reference values. All the analyzed variables showed a statistically significant reduction $(\mathrm{p}<0.001)$ when compared to their reference values.
Table 2 - Functional parameters of preoperative evaluation

\begin{tabular}{lcccc}
\hline Variables & Mean \pm SD & $\begin{array}{c}\text { Mean } \pm \\
\text { SD Pred. }\end{array}$ & Pred. \% & p-value \\
MIP & $50.0 \pm 30.6$ & $90.9 \pm 13.8$ & 59.4 & $<0.001$ \\
MEP & $66.7 \pm 19.7$ & $90.5 \pm 18.2$ & 80.0 & $<0.001$ \\
FVC & $2.4 \pm 0.6$ & $3.3 \pm 0.8$ & 73.0 & $<0.001$ \\
FEV1 & $2.2 \pm 0.6$ & $2.7 \pm 0.6$ & 82.5 & $<0.001$ \\
FEV1/FVC & $0.9 \pm 0.1$ & & 91.3 & $<0.001$ \\
6MWT & $463.2 \pm 129.8$ & $583.1 \pm 108.0$ & 81.0 & $<0.001$ \\
Pulmonary & $27.4 \pm 8.8$ & & & $<0.001$ \\
pressure & & & & \\
\hline
\end{tabular}

Note: MIP: maximal inspiratory pressure; MEP: maximal expiratory pressure; FVC: forced vital capacity; FEV1: forced expiratory volume in one second; 6MWT: six-minute walking test; Pred.: predicted.

Regarding handgrip strength (HGS), $76.7 \%$ of the patients $(n=23)$ presented a normal muscle strength, $10 \%(\mathrm{n}=3)$ demonstrate results above the predicted values for their age, and $13.3 \%(n=4)$ showed values lower than the expected.

Data obtained in preoperative evaluation, risk factors for postoperative pulmonary complications (PPCs) and the classification of PPCs are demonstrated in Table 3 .

Table 3 - Preoperative information, risk factor and PPCs types

\begin{tabular}{lcc}
\hline Variables & Median $\left[1^{\circ} \mathrm{Q} ; 3^{\circ} \mathrm{Q}\right]$ & $\mathrm{N}(\%)$ \\
Hospitalization (days) & $2[2 ; 3]$ & \\
ICU days & $0[0 ; 0]$ & \\
MV days & $0[0 ; 0]$ & \\
Number of patients & & \\
in ICU & & $2(6.7)$ \\
Number of patients & & \\
in MC & & $1(3.3)$ \\
Risk score & & \\
High risk & $0[-4 ; 5]$ & $19(63.3)$ \\
Low risk & & $11(36.6)$ \\
& & \\
PPCs & & \\
Without complications & & $7(23.3)$ \\
Type I & & $3(10.0)$ \\
Type II & & $1(63.3)$ \\
Type III & & $1(3.3)$ \\
\hline
\end{tabular}

Note: $1^{0}$ Q: first quartile; $3^{0}$ Q: third quartile; ICU: intensive care unit; MV: mechanical ventilation; PPCs: postoperative pulmonary complications.

In Table 4 significant correlations between preoperative evaluated parameters, postoperative pulmonary complications, and postoperative data. 
Table 4 - Correlation between preoperative evaluation, PPCs and post-surgery outcome

\begin{tabular}{|c|c|c|c|c|c|}
\hline & PPCs & MEP & PMS & 6MWT & ICU \\
\hline MIP & $\begin{array}{l}r=-0.39 \\
p=0.032\end{array}$ & $\begin{array}{l}r=0.59 \\
p<0.001\end{array}$ & $\begin{array}{l}r=0.42 \\
p=0.01\end{array}$ & $\begin{array}{l}r=0.40 \\
p=0.02\end{array}$ & - \\
\hline MEP & - & - & $\begin{array}{l}r=0.62 \\
p<0.001\end{array}$ & - & - \\
\hline PMS & - & - & - & $\begin{array}{l}r=0.36 \\
p=0.04\end{array}$ & - \\
\hline MV & $\begin{array}{l}r=0.36 \\
p=0.04\end{array}$ & - & - & - & $\begin{array}{l}r=0.69 \\
p<0.001\end{array}$ \\
\hline Hospitalization days & $\begin{array}{l}r=0.40 \\
p=0.02\end{array}$ & - & - & - & $\begin{array}{l}r=0.40 \\
p=0.02\end{array}$ \\
\hline
\end{tabular}

Note: MIP: maximal inspiratory pressure; MEP: maximal expiratory pressure; PPCs: postoperative pulmonary complications; PMS: peripheral muscle strength; 6MWT: six-minute walking test; MV: mechanical ventilation; ICU: intensive care unit.

\section{Discussion}

The inverse correlation between MIP and PPCs indicates that the lower is MIP, the greater is the risk of developing complications. This fact may be justified by the results of Hulzebos et al. [17] study, in which several risk factors for PPCs and respiratory muscle weakness were associated with a high incidence of PPCs and pneumonia, and with a prolonged postoperative hospitalization.

Morano et al. [4] observed a high incidence of PPCs, an extended time of intubation and hospitalization in patients that presented average MIP values of $67.6 \pm 39.9 \mathrm{cmH} 20$. In the present study, this average was $50.03 \pm 30.59 \mathrm{cmH} 20$. According to ATS/ERS [24] guidelines regarding pulmonary function tests, MIP values lower than $80 \mathrm{cmH} 20$ may indicate respiratory muscle weakness, therefore, increase the risk of developing PPCs and worsening postoperative recovery. The results of the present study demonstrate that, beyond respiratory muscle weakness, $63.3 \%$ of the patients present a high risk of developing PPCs.

Abreu and collaborators [25] evaluated 20 women before breast cancer surgery and reported a lower MIP average value when compared to the ones demonstrated in the present study $(43.1 \%$ and $59.4 \%$ of the predicted value, respectively). The results of the MEP values were also lower than those found in the present study $(40.1 \%$ and $80.0 \%$ of the predicted value, respectively). These results highlight the reduction of respiratory muscle strength of oncological patients.

Hulzebos et al. [16] evaluated patients that underwent myocardial revascularization surgery and defined some predictive factors for PPCs. Among them, MIP and MEP values similar or higher than $75 \%$ of the predicted value were considerate protective factors for PPCS. Also, it was found a correlation between preoperative respiratory muscle strength with PPCs. Although the present study analyzed oncological patients, similar results were found. Another study made my Hulzebos et al. [17] showed a reduction of PPCs in patients who presented MIP average value of $95.6 \mathrm{cmH} 20$.

When considering the risk factors for PPCs, Hulzebos et al. [16] demonstrate that most of the patients showed high chances of developing these complications. This result may be explained by patients' profile, once $53.4 \%$ of them had a smoking background, $30 \%$ had respiratory diseases, $40 \%$ presented a productive cough, $10 \%$ were diabetic, and $36.7 \%$ had BMI higher than 27.

Saad et al. [26] aimed to identify risk factor for PPCs in 145 patients that underwent thoracic cancer surgery. From 27 patients who presented pulmonary complications, 26 had a smoking background. Brooks-Brunn [27] defined BMI higher than 27 as a risk factor for PPCs and, among the patients of the present study, $36.7 \%$ presented this index. Riedi et al. [15] evaluated the relationship between respiratory muscle strength and PPCs in cardiac surgeries and observed that $41.6 \%$ of the patients presented overweight, which was considered a contributing factor for a low survival rate $[28,29]$.

In the present study, mechanical ventilation and hospitalization time had a significant correlation with the type of PPCs. The most frequent complication was PPCs type II with $63.3 \%$ of the cases. Van Adrichem et al. [10] evaluated individuals who underwent an esophagectomy and had similar results, showing that $61.5 \%$ of the patients presented complications of type I and II. Therefore, it is suggested that the patients of this study 
had less grave complications due to the fact they remained hospitalized for a short period and only a few of them was sent to ICU, once the majority of the surgeries were of low complexity.

Patients who spent more time in ICU and needed MV were the ones who presented the worst complications, also because they remained hospitalized for a longer time when compared to the ones of PPCs type I and II. These results were similar to the ones presented by a Dutch study, in which the patients who had complications of type I and II spent less time hospitalized when compared to the patients with PPCs type II and IV [10].

Reeve et al. [7] studied patients who underwent a pulmonary resection by thoracotomy. The researchers verified that patients with PPCs spent more time hospitalized than the patients who did not present PPCS, with an average of 17 and six days of hospitalization, respectively.

The time in ICU was also correlated with the days of hospitalization. Thus, it is suggested that this correlation is because ICU patients are usually in a critical condition, need special care and might present worse pulmonary complications, therefore, remain a longer time in hospital.

In a study published in 2011, patients who were exposed to pulmonary resection were analyzed. Individuals that presented better respiratory strength and pulmonary function spent less time in ICU (average of 14.9 \pm 44.7 ) and stayed fewer days in the hospital (average of $6.3 \pm 3.0$ ) when compared to the time spent in ICU (average of $40.5 \pm 75.2$ ) and hospital (average of 11.0 \pm 6.3 ) of patients with worse pulmonary conditions [14].

By the results of the present study and other scientific publications, it is possible to confirm that the incidence of PPCs requires a greater care at this time, increasing the risk of this patients to stay in ICU in postoperative and remain an extended time in the hospital $[7,14,17,4,10]$.

Preoperative functional conditions may influence the rehabilitation process. In the present work, the average of respiratory muscle strength (MIP: 50.03 \pm 30.59 ; MEP: $66.7 \pm 19.66$ ) and pulmonary function (FVC: $2.40 \pm 0.56$; FEV1: $2.17 \pm 0.56$ ) values demonstrated that these variables are lower in postoperative patients, and this fact if directly associated with PPCs increase.

Nakamura et al. [30] analyzed the factors that might contribute to the reduction of pulmonary complications incidence after esophagectomy. The researchers reported factors that are related to PPCs incidence, among them, preoperative respiratory physiotherapy. Studies demonstrated that preoperative respiratory physiotherapy increases FVC,
FEV1, respiratory muscle strength and functional capacity $[4,5,10,14]$. This kind of physiotherapy is also associated with the reduction of PPCs and hospitalization time $[4,10,17]$, which corroborate the present results.

Some limitations were found in the present study. One of them was the sample number, which precluded the evaluations of patients by specific types of surgeries. The other was the lack of postoperative evaluations, which were not performed because patients were not able to move to the Educational Clinic, then the outcomes of surgeries were not analyzed.

\section{Conclusion}

The correlations found in the present study demonstrate that a healthy physical condition and a good pulmonary function before oncological surgery enable a better prognostic in postoperative.

\section{References}

1. International Agency for Research on Cancer. 2018 [cited 2019 Dec 10]. Available from: https://tinyurl. com/ybejygbo

2. Bray F, Ferlay J, Soerjomataram I, Siegel RL, Torre LA, Jemal A. Global cancer statistics 2018: GLOBOCAN estimates of incidence and mortality worldwide for 36 cancers in 185 countries. CA Cancer J Clin. 2018;68(6):394-24.

3. Instituto Nacional de Câncer José Alencar Gomes da Silva. Estimativa 2018: Incidência de Câncer no Brasil. Rio de Janeiro: INCA; 2017.[cited 2019 Dec 10]. Available on: https://tinyurl.com/y9ooec85

4. Morano MT, Araújo AS, Nascimento FB, Silva GF, Mesquita R, Pinto JS, et al. Preoperative pulmonar rehabilitation versus chest physical therapy in patients undergoing lung cancer resection: A pilot randomized controle trial. Arch Phys Med Rehabil. 2013;94(1):53-8.

5. Dronkers JJ, Lamberts H, Reutelingsperger IMMD, Naber RH, Dronkers-Landman CM, Veldman A, et al. Preoperative therapeutic programme for elderly patients scheduled for elective abdominal oncological surgery: A randomized controlled pilot study. Clin Rehabil. 2010;24(7):614-22. 
6. Reeve JC, Nicol K, Stiller K, McPerson KM, Denehy L. Does physiotherapy reduce the incidence of postoperative complications in patients following pulmonar resection via thoracotomy? A protocol for a randomized controlled trial. J Cardiothorac Surg. 2008;3(48):1-10.

7. Reeve JC, Nicol K, Stiller K, McPerson KM, Birch P, Gordon IR, et al. Does physiotherapy reduce the incidence of postoperative pulmonar complications following pulmonary resection via open thoracotomy? A preliminary randomized single-blind clinical trial. Eur J Cardiothorac Surg. 2010;37(5):1158-67.

8. Torres SMRR. Estudo randomizado para avaliação da eficácia da fisioterapia respiratória no pré-operatório de pacientes submetidos a tratamento cirúrgico de câncer de boca, laringe e faringe [master's thesis]. São Paulo: Universidade de São Paulo; 2010.

9. Agrelli TF, Ramos MC, Guglielminetti R, Silva AA, Crema E. Preoperative Ambulatory Inspiratory Muscle Training in Patients Undergoing Esophagectomy. A Pilot Study. Int Surg. 2012;97(3):198-202.

10. Van Adrichem EJ, Meulenbroek RL, Plukker JTM, Groen $\mathrm{H}$, van Weert E. Comparisom of two preoperative inspiratory muscle training programs to prevent pulmonar complications in patients undergoing esophagectomy: A randomized controlled pilot study. Ann Surg Oncol. 2014;21(7):2353-60.

11. Bellinetti LM, Thomson JC. Respiratory muscle evaluation in elective thoracotomies and laparotomies of the upper abdomen. J Bras Pneumol. 2006;32(2):99-100.

12. Tuttle TM, Burke EE. Bilateral Mastectomy: Doubling Down on Complications? Ann Surg Oncol. 2015;22(11):3407-08.

13. Matsuda A, Matsumoto S, Seya T, Matsutani T, Kishi T, Yokoi K, et al. Does Postoperative Complication Have a Negative Impact on Long-Term Outcomes Following Hepatic Resection for Colorectal Liver Metastasis?: A MetaAnalysis. Ann Surg Oncol. 2013;20(8):2485-92.

14. Benzo R, Kelley GA, Recchi L, Hofman A, Sciurba F. Complications of lung resection and exercise capacity: a meta-analysis. Respir Med. 2007;101(8):1790-7.

15. Riedi C, Mora CTR, Driessen T, Coutinho MCG, Mayer DM, Moro FL, et al. Relation between respiratory muscle strength with respiratory complication on the heart surgery. Rev Bras Cir Cardiovasc. 2010;25(4):500-5.
16. Hulzebos EH, Van Meeteren NL, De Bie RA, Dagnelie PC, Helders PJ. Prediction of postoperative pulmonary complications on the basis of preoperative risk factors in patients who had undergone coronary artery bypass graft surgery. Phys Ther. 2003;83(1):8-16.

17. Hulzebos EHJ, Helders PJM, Favié NJ, De Bie RA, De La Riviere AB, Van Meeteren NLU. Preoperative Intensive Inspiratory Muscle Training to Prevent Postoperative Pulmonary Complications in High-Risk Patients Undergoing CABG Surgery: A Randomized Clinical Trial. JAMA. 2006;296(15):1851-57.

18. Neder JA, Andreoni S, Lerario MC, Nery LE. Reference values for lung function tests II. Máximal respiratory pressures and voluntary ventilation. Braz J Med Biol Res. 1999;32(6):719-27.

19. ATS statement: Guideline for six-minute walk test. Am J Respir Crit Care Med. 2002;166(1):111-7.

20. Enrigth PL, Sherrill DL. Reference equations for the sixminute walk in health adults. Am J Respir Crit Care Med. 1998;158(1):1384-7.

21. Marino DM, Marrara KT, Ike D, Oliveira Jr AD, Jamami M, Di Lorenzo VA. Study of peripheral muscle strength and severity indexes in individuals with chronic obstructive. Physiother Res Int. 2010;15(3):135-43.

22. Manual do usuario - Dinamómetro Electrónico Camry Mod: EH101. Valencia: General ASD.

23. Cohen J.Statistical Power Analysis for the Behavioral Sciences. 2nd ed. New York: Lawrence Erlbaum Associates;1988.

24. American Thoracic Society/European Respiratory Society. ATS/ERS Statement on respiratory muscle testing. Am J Respir Crit Care Med. 2002;166(4):518-624.

25. Abreu APM, Endres D, Costa AB, Zanini SCC, Martini RR, Leguisamo CP. Função Pulmonar e Força Muscular Respiratória em Pacientes Submetidas à Cirurgia Oncológica de Mama. Rev Bras Cancerol. 2014;60(2):151-7.

26. Saad IAB, Capitani EM, Toro IFC, Zambon L. Clinical variables of preoperative risk in thoracic surgery. Sao Paulo Med J. 2003; 121(3):107-10.

27. Brooks-Brunn JA. Postoperative atelectasis and pneumonia: risk factors. Am J Crit Care. 1995;4(5):340-49.

28. Morch KT, Leguisamo CP, Camargo MD, Coronel CC, Mattos WO, Leila DN, et al. Perfil ventilatório dos pacientes submetidos a cirurgia de revascularização do miocárdio. Rev Bras Cir Cardiovasc. 2009;24(2):180-7. 
29. Cho H, Yoshikawa T, Oba MS, Hirabayashi N, Shirai J, Aoyama T, et al. Matched Pair Analysis to Examine the Effects of a Planned Preoperative Exercise Program in Early Gastric Cancer Patients with Metabolic Syndrome to Reduce Operative Risk: The Adjuvant Exercise for General Elective Surgery (AEGES) Study Group. Ann Surg Oncol. 2014;21(6):2044-50.
30. Nakamura $M$, Iwahashi $M$, Nakamori M, Ishida K, Naka T, Iida T, et al. An analysis of the factors contributing to a reduction in the incidence of pulmonary complications following an esophagectomy for esophageal cancer. Langenbecks Arch Surg. 2008;393(2):127-33.

Received: 09/29/2018

Recebido: 29/09/2018

Approved: 02/03/2020

Aprovado: 03/02/2020 